\title{
Educação e moral na perspectiva republicana
}

Fábio César Junges ${ }^{1}$, Tiago Anderson Brutti ${ }^{2}$, Elizabeth Fontoura Dorneles ${ }^{3}$

\section{Resumo}

Ao tematizar a condição humana, o sistema educacional e os critérios e propósitos de uma Constituição republicana, este artigo, de caráter exploratório e bibliográfico, articula as arguições de Sêneca e de Rousseau sobre os temas da moral e da educação; as considerações de Tugendhat a respeito dos sentidos em que se pode entender a palavra moral; e as narrativas e argumentos de Andrada e Silva em defesa da igualdade, da educação e da integração dos trabalhadores negros e dos nativos brasileiros à sociedade nacional. Esse repositório de ideias converge em muitos pontos com as proposições de Condorcet, cujos textos representam uma coleção de justificativas para a instituição da república e a organização de um sistema de educação comprometido com o imaginário moral republicano; e as teses de Freire, para quem a educação constitui um espaço privilegiado para a autonomia, a crítica e a emancipação, condições fundamentais para a transformação de uma realidade opressora. Freire se aproxima, por assim dizer, do iluminismo de Rousseau e de Condorcet, diferenças à parte, ao propor uma linguagem de esperança para o campo da educação, para além das teorias da reprodução, compreendendo que os estudantes são capazes de interpretar de modo ativo a sua própria situação e de resistir aos grupos e às forças que tentam fazer prevalecer as suas orientações de dominação.

\section{Palavras-chave}

Condição humana. Constituição. Educação. República. Sociedade moral.

\footnotetext{
${ }^{1}$ Doutor em Teologia pelas Faculdades EST, Rio Grande do Sul, Brasil; com estágio pós-doutoral em Práticas Socioculturais e Desenvolvimento Social pela Universidade de Cruz Alta, Rio Grande do Sul, Brasil; professor substituto na Universidade Federal da Fronteira Sul, Rio Grande do Sul, Brasil. E-mail: fabiocesarjunges@yahoo.com.br.

${ }^{2}$ Doutor em Educação nas Ciências - Filosofia pela Universidade Regional do Noroeste do Estado do Rio Grande do Sul, Brasil com período sanduíche na Facultad de Formación de Profesorado y Educación da Universidad Autónoma de Madrid, Espanha; estágio pós-doutoral em Filosofia pela Universidade Estadual do Oeste do Paraná, Brasil; professor adjunto I na Universidade de Cruz Alta, Rio Grande do Sul, Brasil. E-mail: tbrutti@unicruz.edu.br.

${ }^{3}$ Doutora em Letras pela Universidade Federal do Rio Grande do Sul, Brasil; professora da Universidade de Cruz Alta, Rio Grande do Sul, Brasil; membro do Grupo de Estudos, Pesquisa e Extensão em Linguagem e Comunicação (GEPELC) e do Grupo de Estudos e Pesquisas em Análise do Discurso (GEPAD). E-mail: edorneles@unicruz.edu.br.
} 


\title{
Education and moral in the republican perspective
}

Fábio César Junges ${ }^{4}$, Tiago Anderson Brutti ${ }^{5}$, Elizabeth Fontoura Dorneles ${ }^{6}$

\begin{abstract}
In the thematic area of the human condition, the educational system, and the criteria and purposes of a republican constitution, this article articulates the arguments of Seneca and Rousseau on the themes of morality and education; Tugendhat's considerations about the meanings in which the word moral can be understood; and the narratives and arguments of Andrada e Silva in defense of equality, education and integration of black workers and Brazilian natives to the national society. This repository of ideas converges on many points with Condorcet proposals, texts that represent a collection of justifications for institution of the republic and the organization of an education system committed to the republican moral imaginary; and the thesis of Freire, for those who the education establish a privileged space for autonomy, criticism and emancipation, fundamental conditions for the transformation of an oppressive reality. Freire approaches the Enlightenment of Rousseau and Condorcet, differences in part, propose a language of hope for the field of education, to beyond the theories of reproduction, understanding that the students are able to interpret actively their own situation and resist to the groups and forces that try to do prevail their orientations of domination.
\end{abstract}

\section{Keywords}

Human condition. Constitution. Education. Republic. Moral society.

\footnotetext{
${ }^{4} \mathrm{PhD}$ in Theology, Faculdades EST, State of Rio Grande do Sul, Brazil; with post-doctoral internship in Sociocultural Practices and Social Development at the University of Cruz Alta, State of Rio Grande do Sul, Brazil; substitute professor at the Federal University of Fronteira Sul, State of Rio Grande do Sul, Brazil. Email: fabiocesarjunges@yahoo.com.br.

${ }^{5} \mathrm{PhD}$ in Education in Science - Philosophy, Regional University of the Northwest of the State of Rio Grande do Sul, Brazil with a sandwich period at the Faculty of Formación de Profesorado y Educación of the Universidad Autónoma de Madrid, Spain; post-doctoral internship in Philosophy at the State University of Western Paraná, State of Paraná, Brazil; adjunct professor I at Cruz Alta University, State of Rio Grande do Sul, Brazil.E-mail: tbrutti@unicruz.edu.br.

${ }^{6} \mathrm{PhD}$ in Letters, Federal University of Rio Grande do Sul, State of Rio Grande do Sul, Brazil; professor at the University of Cruz Alta, State of Rio Grande do Sul, Brazil; member of the Group for Studies, Research and Extension in Language and Communication (GEPELC) and for the Group for Studies and Research in Discourse Analysis (GEPAD). E-mail: edorneles@ unicruz.edu.br.
} 


\section{Introdução}

As tematizações aqui formalizadas a respeito da condição humana e da viabilidade de se instituir politicamente um cuidado com a educação dos indivíduos e da comunidade, que não prescinda, entre seus intentos, de discutir uma arte, uma filosofia e uma ciência enredadas com os critérios e propósitos de uma sociedade cuja normatividade se afirme à luz de uma Constituição republicana, devem ser compreendidas, neste texto, como vinculadas ao entendimento segundo o qual nossa compreensão, não obstante somente possível no interior de uma complexa e singular configuração orgânica e social, é linguagem, a "casa do ser" (HEIDEGGER, 2005, p. 8), e, como tal, por operar intersubjetivamente, sugere polissêmicas interpretações de mundo e de subjetividade.

Nesse complexo meio entre os seres de linguagem é que se notabilizam possibilidades de relações, familiarizando-nos com interpretações plurais, o que torna possível organizar um mundo comum cujos sentidos e estruturas não devem, contudo, ser supostos como decorrentes, simplesmente, de códigos preestabelecidos ou de apostas inexoráveis que tenham se sedimentado historicamente como as melhores escolhas, a tal ponto que pudessem essas decorrências supostas, por si sós, nos autorizarem a dispensar justificativas reciprocamente aceitáveis nas peculiares circunstâncias em que compreendemos e interpretamos, a cada vez, o contexto de vivências no nosso próprio tempo e espaço.

É de Aristóteles a proposição político-antropológica de que os seres humanos são seres de linguagem (GADAMER, 2002). Mas é somente no século passado que o ser humano passa a se compreender nas ciências humanas, em seu pensar e agir, como um ser de linguagem. Retomando a tradição grega, as ciências humanas têm como standard de racionalidade a compreensão de que o ser humano é o único ser que possui a capacidade de comunicar tudo o que pensa pela linguagem.

É sempre sob os termos da linguagem, do diálogo, que o ser humano é capaz de organizar o seu mundo em toda a sua complexidade possível. A organização do trabalho, transporte, comunicação, política, justiça, educação, valores, enfim, tudo o que está implicado na convivência de uns com outros, com a pretensão de constituir um mundo comum, tem na linguagem a base fundante. Isso manifesta que nos constituímos como seres vivos "dotados de linguagem" (GADAMER, 2002, p. 227).

Segundo Gadamer (2002), interpretamos a nós mesmos, aos outros e ao mundo em geral sempre e primeiramente como linguagem. Movimentamo-nos sempre em situações de diálogo que têm na dialética da pergunta e da resposta seu modo de ser fundamental. É a 
partir da linguagem que "nos entendemos e pela qual articulamos nosso mundo comum" (GADAMER, 2002, p. 13). A condição humana expressa em suas diversas narrativas tem a linguagem como seu ethos. A política é a expressão mais elaborada desse ethos, uma vez que ela pressupõe a possibilidade de que os envolvidos manifestem suas opiniões por meio da palavra e do dizer como querem a organização do mundo do qual fazem parte, e a liberdade de expressar-se na sua singularidade e pluralidade de modos de ser, e de pensar na perspectiva da constituição de um mundo comum.

Este texto apresenta, na primeira parte, um quadro da interpretação de Dalbosco a respeito das arguições de Sêneca e de Rousseau no que se refere à moral e à educação natural. Articula, na segunda parte, considerações de Tugendhat acerca dos sentidos em que se pode entender a palavra moral e, ainda, discursos parlamentares de Silva em defesa da igualdade dos negros e dos nativos brasileiros ${ }^{7}$. Essa articulação, por fim, é carreada para os argumentos de um contemporâneo de Silva, o filósofo Condorcet, cujos textos representam uma coleção de boas justificativas para a instituição da república e para a organização de um sistema de educação comprometido com o imaginário moral republicano. Por fim, esta pesquisa busca estabelecer um diálogo entre esse repositório de ideias e as teses de Freire, autor para quem de pouco valeria a transformação estrutural e objetiva da realidade opressora se não fosse acompanhada da transformação subjetiva e intersubjetiva das consciências, condição que a educação poderia produzir, compreendendo-se a escola, desse modo, como espaço público de discussão, argumentação e diálogo, e, além disso, como instituição onde tendencialmente todos aprendem a tomar e a dizer sua palavra de forma crítica e autônoma.

\section{Educação natural em Sêneca e Rousseau}

Ao comentar o pensamento filosófico-pedagógico de Rousseau, Dalbosco (2011) compreende que o autor genebrino é marcadamente inspirado pela filosofia de Sêneca: primeiro, por defender a tese da sociabilidade da moral; segundo, por atribuir um papel normativo à natureza como fonte primeira de regulação do comportamento do educando; e, terceiro, por atribuir ao educador, também entendido como governante, o papel de responsável pela inserção da criança na ordem das coisas, ou seja, o papel de principal mediador ou condutor da relação que ela constrói com o mundo externo. A afirmação de tais

\footnotetext{
${ }^{7}$ Trata-se dos discursos proferidos em 1823: Apontamentos para a civilização dos índios bravos do Império do Brasil e Representação à Assembleia Geral Constituinte e Legislativa do Império do Brasil sobre a escravatura.
} 
posições vem acompanhada, em Rousseau, de uma forte crítica à origem social dos vícios e, também, de uma justificação da educação natural como resistência à corrupção político-moral.

Para Dalbosco (2011), Sêneca vincula o tema da moral diretamente com a interioridade humana e com sua busca pela vida feliz. As cartas escritas por Sêneca à Lucílio preceituam Deus como princípio ativo criador e movente do universo e, também, o ser humano como ente ligado à divindade por meio da parte racional da alma, através da qual o homem assegura o domínio sobre si mesmo e, assim, alcança a virtude. Essa vinculação da condição humana à ordem cósmica e divina reside no permanente domínio de si mesmo. Esse domínio, por sua vez, é conquistado mediante a descoberta e a contemplação racional das cadeias causais ${ }^{8}$ que tecem a ordem cósmica. Nas cartas para Lucílio, Sêneca indica que a felicidade duradoura repousa na ação virtuosa e que, por isso, a busca pela vida feliz depende da moralidade. Se a ação pedagógica de Sêneca estivesse fundamentada na aridez do discurso filosófico sobre a moral, Lucílio, possivelmente, se afastaria ainda mais dos problemas e preocupações que poderiam inseri-lo no âmago da busca pela vida feliz. Para sensibilizar Lucílio, Sêneca escolheu, então, como ponto de partida, a condição finita da vida humana, para que o exemplo normativo da natureza acalentasse a angústia existencial frente à morte (DALBOSCO, 2011, p. 63-71).

Segundo Dalbosco (2011), Sêneca toma por indispensáveis os preceitos no processo de formação moral, porquanto a virtude, além da parte teórica, também apresenta uma parte prática, sem a qual ela não se efetivaria. Os preceitos operam como estímulo permanente da busca humana pelo bem e, enquanto máximas da ação, indicam a via do cumprimento do dever. Em outros termos, se é pela prática dos deveres que se pode confirmar um juízo sobre o bem e o mal, são os preceitos que conduzem a tal prática. Um indivíduo em processo de formação deve ter reforçadas as indicações que podem conduzi-lo ao domínio da ação correta. Nesse sentido, os preceitos descortinam, por assim dizer, o âmbito da virtude prática, com a finalidade de conduzir alguém a conquistar o domínio sobre si mesmo. Por essa compreensão, a decisão de nos deixarmos guiar enquanto estamos aprendendo a guiar por nós mesmos é uma decisão pedagógico-existencial fundamental que nenhum mestre-pedagogo pode tomar

\footnotetext{
${ }^{8} \mathrm{O}$ eterno desenvolvimento causal do universo é compreendido pelos estoicos como uma concatenação somente de causas, ou seja, de corpos que interagem entre si. Assim, o conceito de causa aplica-se somente a um corpo que está ativamente envolvido em algum processo ou é responsável por algum estado. Sêneca define causa como sendo tudo aquilo que age (id quod facit). Daí a ideia de que o conceito de causa não pode ser pensado como uma sequência linear, no sentido de que um ponto levaria retilineamente a outro, mas sim como uma rede interativa na qual linhas se cruzam entre si (DALBOSCO, 2011, p. 103-104).
} 
em nome de seu educando, mas pode auxiliar decisivamente no convencimento sobre a relevância dessa decisão.

Para Dalbosco (2011), Sêneca compreende que o papel de um preceito consiste em indicar o modo mais adequado de ação em uma determinada circunstância. Tal ação, por essa compreensão, terá maior eficácia se o mestre-pedagogo estiver convencido racionalmente sobre a validade da mensagem inscrita no preceito que a recomenda. Um preceito, desse modo, equivale a uma máxima de ação que abrange a esfera do particular, indicando qual seria o modo mais adequado, por exemplo, do relacionamento entre pais e filhos. Um princípio, diferente de um preceito, trata do universal e, na linguagem moral de Sêneca, significa que trata do sumo bem, devendo, por isso, levar em consideração a vida humana em sua totalidade. Um princípio, nesse sentido, equivale à convicção humana interiorizada de que o bem moral é o maior de todos os bens e, por isso, é nele que deve repousar o conteúdo moral das ações humanas. Um princípio deve servir, por esse caminho, de referência a todos os preceitos que tratam das ações inseridas no fluxo da vida cotidiana. Os princípios são, pois, moralmente indispensáveis, porquanto somente por seu intermédio o homem pode alcançar a compreensão de ser parte de um vasto corpo expressado na ideia de uma natureza criadora de tudo e de todos a partir de uma mesma matéria. Por essa compreensão, o processo formativoeducacional humano não deve desprezar a consciência da pertença do educando à espécie humana e dessa à ordem cósmica ou a uma ideia de totalidade. É por meio da educação por princípios e não somente por preceitos que se chega a essa consciência.

A educação natural ou educação negativa da personagem de Rousseau, o Emílio, corresponde, segundo Dalbosco (2011), mais a uma educação guiada pelas coisas do que a uma educação discursiva baseada na razão. Na primeira fase de educação do Emílio, a ênfase do processo pedagógico recai sobre o fortalecimento do corpo e o refinamento dos sentidos. Posteriormente é que a educação social ou educação positiva do Emílio alcançará o ingresso do educando na vida social adulta. Essa fase complementar será baseada no emprego adequado da razão na determinação racional da vontade e, portanto, no domínio moral de si mesmo. Contudo, esse almejado amadurecimento moral só poderá ser alcançado se a educação negativa for adequadamente desenvolvida. Ou seja, a robustez do corpo e o refinamento dos sentidos são condição necessária, mas não suficiente, do progressivo desenvolvimento cognitivo e moral do educando.

Para Dalbosco (2011), é necessário, a fim de compreender o alcance da originalidade de Rousseau no campo pedagógico, reconhecer que a filosofia do autor genebrino não se entusiasma com o poder emancipador da razão humana, antes implica uma crítica da razão ao 
defender o regresso à natureza como retorno à interioridade humana. É enquanto crítico da razão que ele avalia o modo como as crianças eram tratadas em sua época e, ao mesmo tempo, justifica a importância pedagógica de serem respeitadas como crianças, isto é, em seu próprio mundo e modo de ser.

Rousseau é reconhecido por Dalbosco (2011) como um precursor da dialética da razão. Toma-se a expressão para indicar o fato de que, quando se trata de ação e de história humanas, não se pode reduzir a verdade a uma versão ou a um só lado dos acontecimentos. Nesse sentido, a dialética da razão significa o esforço da razão reflexiva de observar as coisas, as relações e os acontecimentos em sua historicidade, considerando-os por diferentes ângulos sem absolutizá-los. No contexto do pensamento de Rousseau, a dialética da razão se expressa como capacidade de pensar em forma de paradoxos e isso significa desenvolver a capacidade reflexiva de perceber os conflitos inerentes à vida humana e buscar contorná-los da melhor maneira. Trata-se de conceber o ser humano e suas ações de modo amplo, considerando seus sentimentos, suas paixões e seus afetos também como constitutivos de seu agir racional.

Na crítica de Rousseau à ciência e às artes transparece, na compreensão de Dalbosco, a tese segundo a qual o processo de socialização provoca no ser humano a perda de sua unidade consigo mesmo através da dependência do olhar dos outros. Por essa via, sentir-se alienado significa, ao mesmo tempo, sentir-se incapaz de decidir por conta própria. A formação de um aluno soberano e autônomo implica, então, formá-lo racionalmente com capacidade argumentativa. A educação proposta por Rousseau exige, portanto, o emprego da razão, mas não a tomando como um mero procedimento dirigido a fins. Antes disso, segundo Dalbosco (2011), Rousseau buscou ampliar o conceito de razão incluindo nele a dimensão sensível do ser humano. Dimensão implicada com a sociabilidade moral e a tese forte de ouvir a voz da consciência como critério do julgamento moral de nossas ações. É com base nessa compreensão que o autor genebrino busca fundamentar seu projeto de educação natural.

Para Dalbosco (2011), Rousseau apresenta um conceito de liberdade que não representa uma contradição em relação ao domínio de si mesmo. Trata-se de uma liberdade bem regrada ou da liberdade da vontade de agir mediante leis. Essa liberdade significa muito mais do que o agir segundo uma vontade particular ou com o livre arbítrio. Somente quando o Emílio alcançar o estágio de poder dominar-se a si mesmo, isto é, de poder determinar sua vontade mediante leis, é que ele poderá considerar-se livre no sentido moral. Antes disso, ele viverá sob o jugo da liberdade natural e, portanto, sua vontade correrá o risco de submeter-se ao comando de uma liberdade desregrada. 
A importância atribuída ao cuidado de si como ponto de partida da educação natural justifica-se, segundo Dalbosco (2011), pelo fato de que é no núcleo da identidade e da autenticidade consigo mesmo que repousa a moralidade das ações humanas. Toda moralidade de nossas ações, nesse sentido, reside no julgamento que fazemos de nós mesmos. Daí a compreensão segundo a qual sem respeito por si mesmo e sem honestidade consigo mesmo não há moralidade. Um dos principais alvos da crítica de Rousseau é o artificialismo reinante na sociedade de sua época, em que se privilegiava mais o mundo do parecer do que o do ser:

\begin{abstract}
Atualmente, quando buscas mais sutis e um gosto mais fino reduziram a princípios a arte de agradar, reina entre nossos costumes uma uniformidade desprezível e enganosa, e parece que todos os espíritos se fundiram num mesmo molde: incessantemente a polidez impõe, o decoro ordena; incessantemente seguem-se os usos e nunca o próprio gênio. Não se ousa mais parecer tal como se é e, sob tal coerção perpétua, os homens que formam o rebanho chamado sociedade, nas mesmas circunstâncias farão todos as mesmas coisas desde que motivos mais poderosos não os desviem. Nunca se saberá, pois, com quem se trata: será preciso, portanto, para conhecer o amigo, esperar-se pelas grandes ocasiões, isto é, esperar que não haja mais tempo para tanto, porquanto para essas ocasiões é que teria sido essencial conhecê-lo. (ROUSSEAU, 1958, p. 14).
\end{abstract}

As ideias concernentes à educação natural assumem, na opinião de Dalbosco (2011), um peso decisivo na arquitetônica dos ideais político-morais de Rousseau: a participação soberana do cidadão adulto na instituição republicana governada pela vontade geral pressupõe um longo processo formativo do homem que deve iniciar já na primeira infância. Por essa compreensão, pode-se dizer que a concretização dos ideais republicanos depende, em boa parte, da execução do projeto de uma educação natural.

\title{
Sistemas morais e amor à humanidade
}

O âmbito da moral não se pode definir de uma maneira unívoca. Essa é a conclusão de Ernst Tugendhat (2003), filósofo para quem o único elemento determinante nesse âmbito é a capacidade humana de entrar, com base na sua disposição para os sentimentos morais, em sistemas de exigências recíprocas que devem ser justificados reciprocamente. Tal justificação, no entendimento do filósofo, não pode ser pendurada nem na razão nem no céu. A disputa a respeito de como se deve entender a moral tem certos pontos de apoio, mas deixaríamos de ser humanos caso essa disputa pudesse ser decidida de uma maneira definitiva:

[...] a necessidade que os seres humanos têm de colocar em questão a sua própria vida tem a ver com o fato de que, diferentemente das outras espécies, não somos feitos de "arame rígido", senão que podemos duvidar do que 
estamos fazendo e, por conseguinte, também de como conduzimos a nossa vida. [...] trata-se do caminho que devemos tomar na vida, e o característico dos humanos parece ser que isso nunca é óbvio. (TUGENDHAT, 2007, p. 188).

A moral, para o filósofo, pode ser entendida ao menos em três sentidos diferentes: como um sistema aberto de obrigações intersubjetivas, como um comportamento altruísta ou, ainda, como qualquer coisa que cremos dever fazer. Com relação ao sentido da palavra dever, Tugendhat (2003) esclarece que ela pode ser entendida no sentido de obrigações intersubjetivas, mas também pode ter o sentido da pergunta como é para mim bom viver, nesse caso sem o sentido de uma obrigação.

Tugendhat (2003) acredita que as sociedades humanas não poderiam sobreviver, exceto num sistema de obrigações recíprocas. Comparados às outras espécies, nas quais o comportamento altruísta parece ser determinado geneticamente e funcionar por instinto, os humanos se distinguiram com a capacidade de aprender normas, condição que, tanto para o indivíduo quanto para a sociedade, significa maior liberdade e flexibilidade, já que os sistemas de normas podem mudar-se historicamente segundo as condições do meio social.

O filósofo entende que a moral pode encontrar justificativas em duas fontes nãoreligiosas: o interesse próprio, por um lado, e a simpatia e a compaixão, por outro. Contudo, a fonte do interesse próprio tem a prioridade, porque se pressupõe que todos a têm igualmente e também porque só a partir dela se pode entender a geração de um sistema normativo. A compreensão de uma estrutura da moral baseada sobre os interesses implica que cada um seja entendido como disposto a aceitar as normas apenas se os outros também as aceitam. Tal seria o caráter contratualista da moral (TUGENDHAT, 2003).

Outro caráter da moral pode ser encontrado na compreensão de um consenso moral, o qual, diferente de um contrato, não se refere simplesmente às coisas que se devem ou não fazer e aceitar, senão que nos pomos de acordo em louvar ou repreender as mesmas coisas. Isso pode significar que temos sentimentos equivalentes em relação à infração das normas. Isso significa também que nos pomos de acordo sobre um conceito de bom, um conceito em relação ao qual nos louvaremos ou nos repreenderemos mutuamente. Tugendhat (2003) entende que o consenso moral se distingue fundamentalmente de um contrato justamente por se relacionar a um conceito reciprocamente entendido de bom. Nesse sentido, o conceito de um indivíduo moralmente bom tem que estar relacionado aos interesses dos membros de uma sociedade moral, e isso significa que o conceito de bom também tem que estar relacionado ao conceito de bom para cada um.

Tugendhat (2003, p. 22) entende que de uma moral relacionada aos interesses surge 
um conceito de justiça igualitária. Ora, se o sistema não fosse bom igualmente para todos, poderia ser considerado injusto e isso significaria que uma parte dos indivíduos teria que simplesmente aceitar essas normas à força, sem que pudessem ser justificadas. Para o filósofo, o sentido do justo está intimamente imbricado no sentido do moralmente bom. Toda moral, inclusive a religiosa, possui um conceito de justo, conceito que se refere a um dos aspectos do conceito do moralmente bom, justamente o relativo ao equilíbrio entre os indivíduos. Nesse sentido, reconhece-se que em qualquer sistema de normas morais o equilíbrio entre os indivíduos tem que ser determinado de um modo ou de outro. Esse equilíbrio, numa moral religiosa, é determinado pela autoridade religiosa. Já em uma moral que se justifica reciprocamente em relação aos interesses, entende-se que os indivíduos possam engendrar um conceito de equilíbrio igualitário, porquanto por essa justificação cada um terá valor igual.

A própria discussão aberta acerca dos sentidos em que se pode entender a palavra moral nos autoriza a reconhecer o quanto é frágil a condição em que nos encontramos e o quanto é artificial e falível qualquer tentativa de normatização social. Com efeito, as questões morais que, nas circunstâncias atuais da sociedade brasileira, vem sendo amplamente reconhecidas como critérios e propósitos que se destinam a instituir estruturas de proteção social e ações educacionais mais compatíveis com o imaginário republicano da igualdade social e da liberdade política, se aproximam do ponto no qual essas questões já foram discutidas e implementadas nas revoluções republicanas levadas a efeito em outras nações. Tais questões, reafirmamos, vêm sendo consideradas centrais no cenário político brasileiro, todavia, integram um projeto de nação que já se discutia durante o período da proclamação da independência, a julgar pelo sentido dos pronunciamentos de um de seus mais notáveis articuladores, o filósofo José Bonifácio de Andrada e Silva.

Silva (1998) compreendia que a abolição da escravatura era condição necessária para que o Brasil firmasse sua independência nacional, justamente porque, sem ela, sequer uma Constituição seria defensável. Para o filósofo, sem liberdade individual não se poderia construir uma civilização. Não se poderia, com efeito, sequer defender uma moralidade e uma justiça enquanto a escravatura fosse admitida no Brasil. Por essas, dentre outras razões, propôs uma lei de libertação dos negros, incluindo providências ainda hoje pensadas como indispensáveis caso realmente se houvesse querido integrar justamente os negros à sociedade nacional ${ }^{9}$.

\footnotetext{
${ }^{9}$ A esse respeito, o fragmento de um de seus projetos: "Art. X. Todos os homens de cor forros, que não tiverem ofício, ou modo certo de vida, receberão do Estado uma pequena sesmaria de terra para cultivarem, e receberão outrossim dele os socorros necessários para se estabelecerem, cujo valor irão pagando com o andar do tempo;
} 
O filósofo também se ocupou de pensar a integração dos nativos brasileiros à sociedade nacional. Opinou à sua época que a civilização desses povos poderia ser organizada nos moldes da civilização europeia, "naquilo que ela tem de melhor", isso porque, segundo ele, muitos dos hábitos europeus como, por exemplo, a cobiça, e também o modo de exercício do poder político, deveriam ser considerados incompatíveis com os princípios que se deveriam afirmar no Brasil. De acordo com os termos encontrados em um de seus projetos apresentados à Assembleia Constituinte, nas aldeias principais deveriam ser instituídas escolas nas quais se ensinassem, além da leitura, da escrita e das contas, também o catecismo, as artes e os ofícios. Nessas escolas deveriam participar os nativos das cercanias e também os brancos e mestiços das povoações vizinhas (SILVA,1998, p. 109).

Silva (1998) advogou que aqueles rapazes nativos que mostrassem mais talentos e instrução nas escolas das aldeias frequentassem, também, aulas de latim e outras ciências úteis nas escolas que deveriam ser estabelecidas, de acordo com seu projeto, em cada capital das províncias. Os nativos que se destacassem deveriam ser sustentados como pensionários do Estado. Para aqueles que demonstrassem mais progresso nas aulas, assim como melhor comportamento, deles se escolheriam os chefes militares, não só para as aldeias, mas também para as outras povoações brasileiras, uma vez que em iguais circunstâncias os nativos deveriam ser favorecidos nessas profissões públicas.

Depois de ter sido afastado, no ano de 1823, de suas funções no Parlamento, por ato do imperador Dom Pedro I, Silva passou a publicizar suas críticas ao modo inconsequente com o qual, segundo ele, se exercia o poder político no Brasil:

Quando os brasileiros acordaram do sono pesado da opressão europeia, quiseram ser um povo livre e independente, e sonhavam gozar da segurança e justiça e das imunidades do direito constitucional; porém, qual será agora o seu abatimento e desesperação, vendo-se enganado e sofrendo males piores que os do antigo sistema colonial? Sem liberdade, sem propriedade, sem segurança legal. E, será inesperado, e impossível, que arrisquem, um dia, tudo para realizarem enfim seus desejos ardentes? (SILVA, 1998, p. 224).

Passar-se-iam cerca de 70 anos até que a escravatura, finalmente, fosse abolida do ordenamento jurídico brasileiro e para que fosse instituída a forma de governo republicana em nosso país. Essas novas configurações sociais já haviam sido alentadas por Silva (1998) nos discursos que integraram sua luta política em favor da instituição de um sistema de instrução

Art. XI. Todo senhor que andar amigado com escrava, ou tiver tido dela um ou mais filhos, será forçado pela lei a dar liberdade à mãe e aos filhos, e a cuidar na educação destes até a idade de quinze anos" (SILVA, 1998, p. 69). 
e da garantia de condições de igualdade social e de liberdade política no Brasil.

\section{Considerações finais}

Melhor sorte que Silva tiveram muitos homens de ação e de espírito que encontraram, seja na Europa seja nas Américas entre os séculos XVIII e XIX, aceitabilidade no meio social para veicularem a convicção segundo a qual os indivíduos deveriam ser salvaguardados do arbítrio dos homens pela força da lei, garantindo-se, com isso, condições de igualdade social e de liberdade política. Para os filósofos e políticos iluministas em geral, todos os indivíduos deveriam poder participar de um sistema educacional que correspondesse aos interesses de uma sociedade moral republicana. Condorcet, um dos notáveis articuladores, assim como Rousseau, desse pensamento revitalizado da filosofia greco-romana, acreditava ser viável despertar e formar nos alunos uma cultura de respeito pelos outros e por si mesmos. Entendia ainda ser inconveniente rejeitar a opinião segundo a qual um sentido moral pudesse ser cultivado nos sentimentos que esses alunos expressavam.

A respeito do pensamento filosófico-pedagógico de Condorcet, o comentarista Charles Coutel enfatiza: "Em uma marcha que se eleva pouco a pouco dos sentimentos às ideias por meio das palavras, os futuros cidadãos estão convidados a reagir ante situações simples evocadas em histórias curtas lidas por seus mestres; essas histórias tomam como marco 'a história da liberdade humana"". O ensino deveria paulatinamente se tornar mais abstrato, mas não menos preciso, até que os alunos aprendessem sobre as leis, as instituições e as declarações de direitos de uma maneira crítica e respeitosa: "Esta educação do cidadão escapa a todo catecismo: as definições são ilustradas pelos motivos, os motivos pelos princípios, e os princípios pelos direitos naturais" (COUTEL, 2004, p. 76-77). Na opinião de Coutel, o esforço de Condorcet se concentra em encontrar as mediações entre o amor de si ou estima de si, o amor familiar, o amor à pátria, o amor à República e o amor à humanidade. Os direitos do homem e o exercício dos direitos políticos deveriam, pois, nesse sentido, ter a humanidade como horizonte e não somente a pátria.

Condorcet compreende a moral no sentido do cultivo de um sentimento de amor à humanidade e não como o resultado de boas relações contratuais. $\mathrm{O}$ sentimento de amor à humanidade é descrito pelo filósofo como aquele de "uma compaixão terna, ativa, por todos os males que afligem a espécie humana, aquele de um horror por tudo aquilo que, nas instituições públicas, nos atos do governo, nas ações privadas, acrescenta novas dores às dores inevitáveis da natureza" (CONDORCET, 1993, p. 147). Condorcet afirma que o 
enfrentamento das desigualdades instituídas é o propósito central da sociedade republicana, com o objetivo de fazer concorrer as forças comuns ao bem-estar dos indivíduos, independentemente dos traços de sua cultura, da cor de sua pele, do gênero sexual a que pertença, da opinião que expresse e da religião que confesse.

Construindo esse raciocínio, o filósofo aposta na capacidade humana de propiciar tanto a destruição das desigualdades instituídas entre as nações quanto os progressos da igualdade em um mesmo povo. É no horizonte dessa compreensão que as noções de civilização e de humanidade são ampliadas a tal ponto que sobrelevam grande parte das diferenças entre os povos e se impõem como sentimento, razão e moral perfectíveis, sempre à beira do fracasso, por isso mesmo carentes de permanente rediscussão e reafirmação.

As considerações precedentes nos permitem observar que esse repositório de ideias converge e dialoga em muitos pontos com a perspectiva da educação popular inspirada em Freire (2016a), particularmente no que diz respeito à tolerância, compreendida pelo autor como uma das qualidades fundantes da vida democrática, um conceito que orienta para o respeito ao diferente, seus sonhos, suas ideias, suas opções e seus gostos. Na perspectiva de Freire (2016b), a dimensão da educação pode inspirar, ao lado disso, a indignação e a resistência contra as transgressões éticas de que são vítimas muitos cidadãos brasileiros. A transformação das consciências oprimidas deverá ser uma obra dos próprios oprimidos. Dessa forma, supera-se a descrença nas pessoas e na sua capacidade de discutir e de transformar para melhor sua realidade. A exemplo de Rousseau e de Condorcet, Freire concebe a educação como um espaço privilegiado para a promoção da autonomia, do espírito crítico e da emancipação dos educadores, dos alunos e da comunidade. Essa aproximação entre os autores não significa que não exista diferenças de pensamento e de contextos, senão que indica a possibilidade de nesses filósofos encontrarmos argumentos comuns para nos opormos à barbárie e para buscarmos minimizar as desigualdades instituídas que oprimem ou causam dependência.

No que diz respeito à educabilidade em Rousseau, Streck (2004) comenta que o filósofo genebrino funde o educar com a própria vida, porquanto pelo menos desde o nascimento o homem se insere em processos de aprendizagem. Isso não ocorre apenas com o homem, mas também com outros seres da natureza. O homem, por essa perspectiva, trafega ao longo de sua vida a distância entre o que é e o que ele pode vir a ser. O autor destaca que o ideário de Rousseau encontra ressonância na América Latina, inspirando diversas lutas políticas. Compreende-se, junto com o comentador, que há possiblidade de estabelecer interlocuções entre a utopia de Rousseau e a de Freire no sentido de uma educação orientada 
para a autonomia e a emancipação das pessoas. Todavia, essa aproximação não significa a ausência de diferenças entre o pensamento dos dois autores.

Num último termo, importa salientar que Freire (1985) reconhece a natureza política da educação, enquanto ato de conhecimento, implicado de forma direta com a pergunta sobre como estamos praticando a educação e a respeito da coerência de nosso discurso com a prática: "O sonho viável exige de mim pensar diariamente a minha prática [...]. A questão do sonho possível tem que ver exatamente com a educação libertadora, não com a educação domesticadora" (FREIRE, 1985, p. 100).

A educação, dessa forma compreendida, deve ser utópica, no sentido de que ela surte efeito a partir da prática da denúncia das injustiças sociais, ao mesmo tempo em que anuncia o sonho possível de uma sociedade menos espoliadora e mais atenta ao interesse das grandes massas populares que estão constituindo as classes sociais dominadas.

\section{Referências}

CONDORCET. Esboço de um quadro histórico dos progressos do espírito humano. Campinas: UNICAMP, 1993.

COUTEL, C. Condorcet: instituir al ciudadano. Buenos Aires: Ediciones del Signo, 2004.

DALBOSCO, C. A. Educação natural em Rousseau: das necessidades da criança e dos cuidados do adulto. São Paulo: Cortez, 2011.

FREIRE, P. Pedagogia da tolerância. São Paulo: Paz e Terra, 2016a.

FREIRE, P. Pedagogia da autonomia: saberes necessários à prática educativa. São Paulo: Paz e Terra, 2016b.

FREIRE, P. Educação: o sonho possível. In: BRANDÃO, C. R. O educador: vida e morte. Rio de Janeiro: Edições Graal, 1985.

GADAMER, H. Verdade e método II. Petrópolis: Vozes, 2002.

GARCIA, C. B. As cidades e suas cenas: a crítica de Rousseau ao teatro. Ijuí: Editora da Unijuí, 1999.

HEIDEGGER, M. Carta sobre o humanismo. São Paulo: Centauro, 2005.

ROUSSEAU, J. Discurso sobre as ciências e as artes. In: Obras de Jean-Jacques Rousseau. Porto Alegre: Globo, 1958.

SILVA, J. B. A. Projetos para o Brasil. São Paulo: Cia. das Letras, 1998. 
STRECK, D. R. Rousseau \& Educação. Belo Horizonte: Autêntica, 2004.

TUGENDHAT, E. Antropologia como filosofia primeira. In: POMMER, A. et al. (org.). Filosofia crítica: festschrift dos 50 anos do curso de filosofia da Unijuí. Ijuí: Editora da Unijuí, 2007.

TUGENDHAT, E. O problema da moral. Porto Alegre: EDIPUCRS, 2003.

Submetido em 28 de agosto de 2019.

Aprovado em 24 de novembro de 2019. 